Int. Z. angew. Physiol. 28, 105--119 (1970)

\title{
Oxygen Debt: Involvement of the Cori Cycle
}

\author{
R. James Barnard, Merie L. Foss, and Charles M. Tipton \\ Exercise Physiology Laboratory, University of Iowa, Iowa City, Iowa
}

Received February 10, 1969

\begin{abstract}
Summary. Tryptophan and quinolinic acid, inhibitors of gluconeogenesis, were used to block the removal of lactate by the liver in order to investigate the involvement of the Cori cycle in oxygen debt. Five male, mongrel dogs were run on a treadmill at $4 \mathrm{mph}$ with a 20 percent grade for $19 \mathrm{~min}$. The mean exercise $\dot{V}_{\mathrm{O}_{2}}$ was $80.67 \pm 3.11 \mathrm{ml} / \mathrm{kg} / \mathrm{min}$ for the control tests while peak arterial lactate values ranged from 3.83 to $4.98 \mathrm{mM} / \mathrm{l}$. When removal of lactate by the liver was blocked, oxygen debt showed a mean reduction of 44 percent. Moreover, oxygen consumption during the last minute of exercise was reduced by 11 percent.

Fasting ( $72 \mathrm{~h}$ ) was used in $1 \mathrm{dog}$ to prevent the accumulation of lactate during exercise. This procedure reduced oxygen debt to the same level as when the removal of lactate by the liver was blocked with tryptophan and quinolinic acid.

The data show that the lactacid as well as the alactacid component is involved in oxygen debt when lactate is being removed by the liver during the recovery period following exercise.
\end{abstract}

Key-Words: Gluconeogenesis - Lactic Acid - Tryptophan - Quinolinic Acid Alactacid Debt.

The phenomenon of oxygen debt, i.e., the excess utilization of oxygen during recovery from exercise, has been of interest to the physiologist since the early work of Meyerhof [28, 29] and of Hill, Long and Lupton $[13,14]$. The classical Hill-Meyerhof hypothesis states that the conversion of lactate back to glucose is responsible for the excess oxygen utilization observed following exercise. This hypothesis was modified by Margaria, Edwards and Dill [27], when they measured oxygen debts at light work loads without any increase in blood lactate. They divided oxygen debt into a lactacid and an alactacid portion. Huckabee [15] again modified the hypothesis of oxygen debt when he presented his "excess lactate" concept. His results showed a good relationship between oxygen debt measurements and excess lactate calculations. A more recent study by Kayne and Alpert [20] has claimed a complete dissociation between lactate removal and oxygen debt. These investigators studied lactate removal and oxygen debt in anesthetized dogs that had been exercised by electrical stimulation of the muscles of the hind legs. They found that hepatectomy did not significantly alter oxygen debt; however, the rate of lactate removal was markedly altered. Other investigators [1] have 
tried to induce oxygen debt by injecting exogenous lactate into experimental animals. Again, no relationship could be found between oxygen consumption and blood lactate concentrations. Thus, at the present time there appears to be no universal agreement on the relationship between lactate removal and the excess oxygen consumption observed following exercise.

Recent investigations by Lardy and his associates $[8,9,33,40]$ have demonstrated that tryptophan and quinolinic acid are potent in vivo inhibitors of gluconeogenesis in the rat liver. These agents effectively block the phosphoenolpyruvate carboxylinase reaction. In the present investigation, tryptophan and quinolinic acid were used to block the uptake of lactate by the liver and thus eliminate the involvement of the Cori cycle in oxygen debt. Since the metabolism of lactate by the liver involves a number of endothermic reactions, one might anticipate a reduction in oxygen consumption when these reactions are eliminated.

\section{Methods}

\section{Preliminary Investigations}

Two preliminary investigations were conducted to test the effectiveness of tryptophan and quinolinic acid ( 20 and $40 \mathrm{mg} / 100 \mathrm{~g}$ of body weight respectively), in blocking gluconeogenesis in the dog and thus eliminating the removal of lactate by the liver. The first dog was anesthetized (Nembutal $30 \mathrm{mg} / \mathrm{kg}$ ) $1 \mathrm{~h}$ after being fed the tryptophan and quinolinic acid. Catheters were inserted into the omocervical artery and into a hepatic and renal vein. Arterial and venous blood samples were then obtained for lactate and glucose determinations at $2.0,2.5$, and $3.0 \mathrm{~h}$ after feeding.

A second dog was $x$ un on the treadmill at $4 \mathrm{mph}$ with a 15 percent grade $1 / 2 \mathrm{~h}$ after having received the tryptophan and quinolinic acid. After $18 \mathrm{~min}$ of running, the treadmill was stopped and the dog was immediately anesthetized. Catheters were again inserted and arterial and hepatic venous blood samples were obtained at 20,50, and 80 min after the run. The data shown in Table 1 demonstrate that the liver was producing lactate as opposed to removing it. These results are similar to those reported by Ray et al. [33] and by Veneziale et al. [40] for liver slices as well as in the isolated, perfused liver. Removal of lactate by the liver doring exereise has been adequately demonstrated in dogs [5] as well as in man $[12,35,36]$. Although the kidney has been implicated as an important gluconeogenic organ [22], its involvement in the Cori cycle during exercise has not as yet been demonstrated and in vivo studies with fasting dogs [19] have shown that after 14 days only a very small net glucose production by the kidney could be demonstrated. The limited data obtained from the kidney in the present study shown that the kidney is capable of removing lactate; however, a net glucose production was not observed. Thus it is assumed that tryptophan and quinolinio acid are also effective in blocking the conversion of laetate to glucose in the kidney if this process does in fact normally occur during exercise.

\section{Experimental Procedures}

Five male, mongrel dogs ranging in weight from 16 to $22 \mathrm{~kg}$ were used as experimental animals. The animals were housed in temperature $\left(72^{\circ}\right)$ and light 
Table 1. The effect of tryptophan and quinolinic acid on lactate and giucose uptake by the liver and kidney

\begin{tabular}{|c|c|c|c|c|c|c|}
\hline \multirow{2}{*}{$\begin{array}{l}\text { Dog No. } 1 \\
\text { Time after feeding } \\
\text { (hours) }\end{array}$} & \multicolumn{3}{|c|}{ Lactate $\mathrm{mM} /$} & \multicolumn{3}{|c|}{ Glucose $\mathrm{mM} / \mathrm{l}$} \\
\hline & Arterial & $\begin{array}{l}\text { Hepatic } \\
\text { venous }\end{array}$ & $\begin{array}{l}\text { Renal } \\
\text { venous }\end{array}$ & Arterial & $\begin{array}{l}\text { Hepatic } \\
\text { venous }\end{array}$ & $\begin{array}{l}\text { Renal } \\
\text { venous }\end{array}$ \\
\hline 2.0 & 2.14 & 2.67 & 2.00 & 5.95 & 5.80 & 5.88 \\
\hline 2.5 & 2.11 & 2.26 & 1.98 & 5.62 & 5.38 & 5.50 \\
\hline 3.0 & 1.91 & 2.07 & - & 5.70 & 5.60 & 5.58 \\
\hline
\end{tabular}

Dog No. 2

Time after run ${ }^{a}(\min )$

\begin{tabular}{lllllll}
\hline 20 & 4.82 & 5.09 & - & 5.14 & 5.34 & - \\
50 & 3.64 & 3.75 & - & 6.08 & 6.10 & - \\
80 & 2.63 & 2.70 & 2.36 & 6.12 & 6.10 & 6.02 \\
\hline
\end{tabular}

a $4 \mathrm{mph}$ with a 15 percent grade for $18 \mathrm{~min}$.

(12 h/day) controlled quarters. One of the dogs (No. 184) had participated in a previous study which involved 6 weeks of training. The other 4 dogs were nontrained but had run on the treadmill several times prior to testing. They also received several training sessions to teach them to sit quietly on the treadmill prior to running. Operations were conducted under aseptic conditions for the implantation of a chronic catheter in the omocervical artery and the performing of a chronic tracheostomy. A laryngectomy tube (No.12) was held in place in the trachea by a vest [7] which was also designed to protect the catheter button. The laryngectomy tubes were kept in the dogs at all times and were inspeeted every 8 to $10 \mathrm{~h}$ for the presence of mucus. At least 10 days of recovery were allowed before any tests were conducted. 2 days before the initial test each dog received a trial run to acquaint him with the feel of the respiratory valve and the rectal probe. At least one day was allowed to elapse between each subsequent test.

Each test consisted of a 19 -min run on the treadmill at $4 \mathrm{mph}$. with a 20 percent grade. Each dog received two control and one tryptophan (tryptophan plus quinolinic aeid) test except dog No, 273 who received only one control and one tryptophan test. Expired air was collected at rest, during the last minute of exercise, and at various times throughout the recovery period. Rectal temperatures were recorded at these same time intervals. Arterial blood samples for lactate and glucose determinations were also obtained throughout the exercise and recovery periods. $1 \frac{1}{2} \mathrm{~h}$ prior to the treadmill run in the tryptophan tests the dogs were fed tryptophan and quinolinic acid (20 and $40 \mathrm{mg} / 100 \mathrm{~g}$ of body weight, respectively) in a small portion of their normal diet. This same amount of food was provided before each control test. $1 \mathrm{~h}$ after feeding, the dogs were taken from the animal quarters to the laboratory. They were fitted with a Collins two-way " $J$ " valve to which a 4 inch plastic tube ( $1 / 2$ inch ID) with an inflatable cuff had been attached. Once the tube had been inserted into the dog's trachea, the cuff was inflated to make the system air tight. When the dog was "quiet", a sample of expired air was collected. An arterial blood sample was also obtained at this time. The temperature probe was then inserted approximately 6 inches into the rectum of the dog and taped to his tail. Temperature was recorded on a Yellow Springs Tele-Thermometer. The actual run on the treadmill started approximately $1 \frac{1}{2} \mathrm{~h}$ after the dog had been fed. One of 
the dogs (No. 272) was given an additional test after $72 \mathrm{~h}$ of fasting. This was done in an attempt to prevent the accumulation of lactate during the exercise period.

\section{Analytical Methods and Calculations}

The expired air was collected in neoprene, latex balloons. Shortly after each collection, a sample of air was transferred to a $50 \mathrm{ml}$ glass syringe which had been coated with mineral oil to make it air tight. The volume of gas in each balloon was then measured by drawing its contents through an American Meter Co. gas meter at a constant rate. The gas meter was calibrated against a spirometer. All volumes were corrected to STPD. Quantitative analyses were done on a micro Scholander and oxygen consumption was than calculated by standard methods [3]. The oxygen consumption values for the linear portion of the recovery curve were placed on data cards and analyzed with a computer by the method of least squares. The regression lines were then placed on graph paper and along with the other oxygen consumption values were used to draw the recovery curves. The oxygen consumption values obtained from the two control tests were used to draw one recovery curve. The means of the resting and last minute of exercise values were used. The area under the curve, i.e., the oxygen debt, was measured with a $\mathrm{K}$ \& $\mathrm{E}$ planimeter (No. 620015).

Arterial blood samples for lactate determinations were immediately transferred to preweighed flasks containing $3 \mathrm{ml}$ of metaphosphoric acid and mixed by shaking. At the conclusion of the test the flasks were again weighed and the contents immediately centrifuged. The supernatant was transferred to vials and stored in a freezer. The samples were analyzed for lactate by the enzymatic method of Marbach and Weil [26]. After a portion of the blood sample had been taken for the lactate determinations, $0.1 \mathrm{ml}$ was pipetted into $1.9 \mathrm{ml}$ of distilled water. The solution was deproteinized by adding $\mathrm{Ba}(\mathrm{OH})_{2}$ and $\mathrm{ZnSO}_{4}$. After centrifugation, the supernatant was analyzed for glucose by the Glucostat method'.

The t-test for matched pairs was used to test for significant differences between the mean control and mean tryptophan measurements.

\section{Results \\ Oxygen Consumption}

The mean resting oxygen consumption value for the control tests was $13.39 \pm 0.71 \mathrm{ml} / \mathrm{kg} / \mathrm{min}$. The values for the 5 dogs ranged from 11.65 to $15.62 \mathrm{ml} / \mathrm{kg} / \mathrm{min}$ (Table 2 ). The mean value for the tryptophan tests was $12.18 \pm 0.80 \mathrm{ml} / \mathrm{kg} / \mathrm{min}$. 4 of the 5 dogs showed a decrease in resting oxygen consumption. The mean reduction during the tryptophan tests was 7.83 percent; however, this reduction was not statistically significant. The resting oxygen consumption for dog No. 272 during the fasting test was $6.73 \mathrm{ml} / \mathrm{kg} / \mathrm{min}$ (Fig. 2).

The oxygen consumption measurements obtained during the last minute of exercise ranged from 72.02 to $88.28 \mathrm{ml} / \mathrm{kg} / \mathrm{min}$ for the control tests. The mean value was $80.67 \pm 3.11 \mathrm{ml} / \mathrm{kg} / \mathrm{min}$ (Table 2 ). The mean difference between the two control tests run on each dog was only

1 Glucostat was obtained from the Worthington Biochemical Corp., Freehold, N. J. 


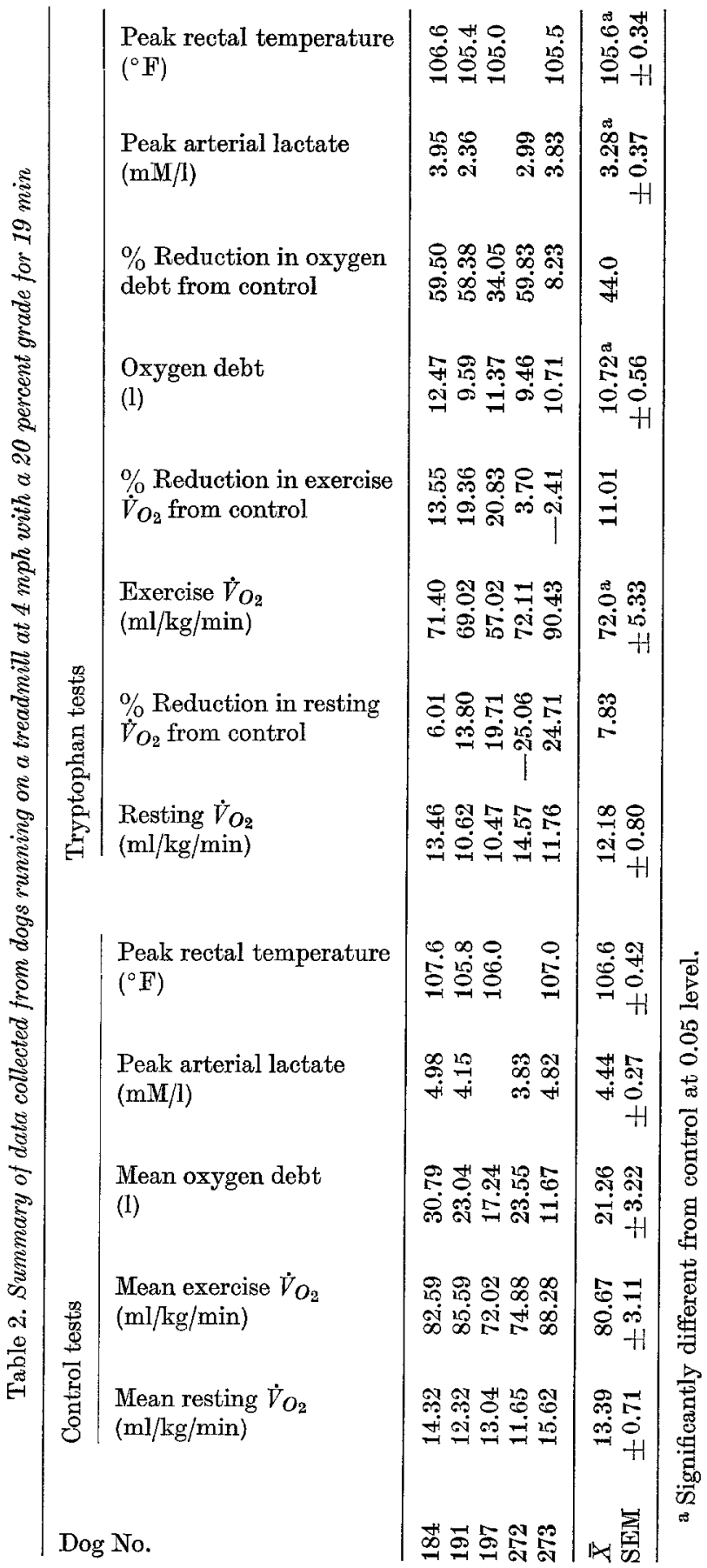



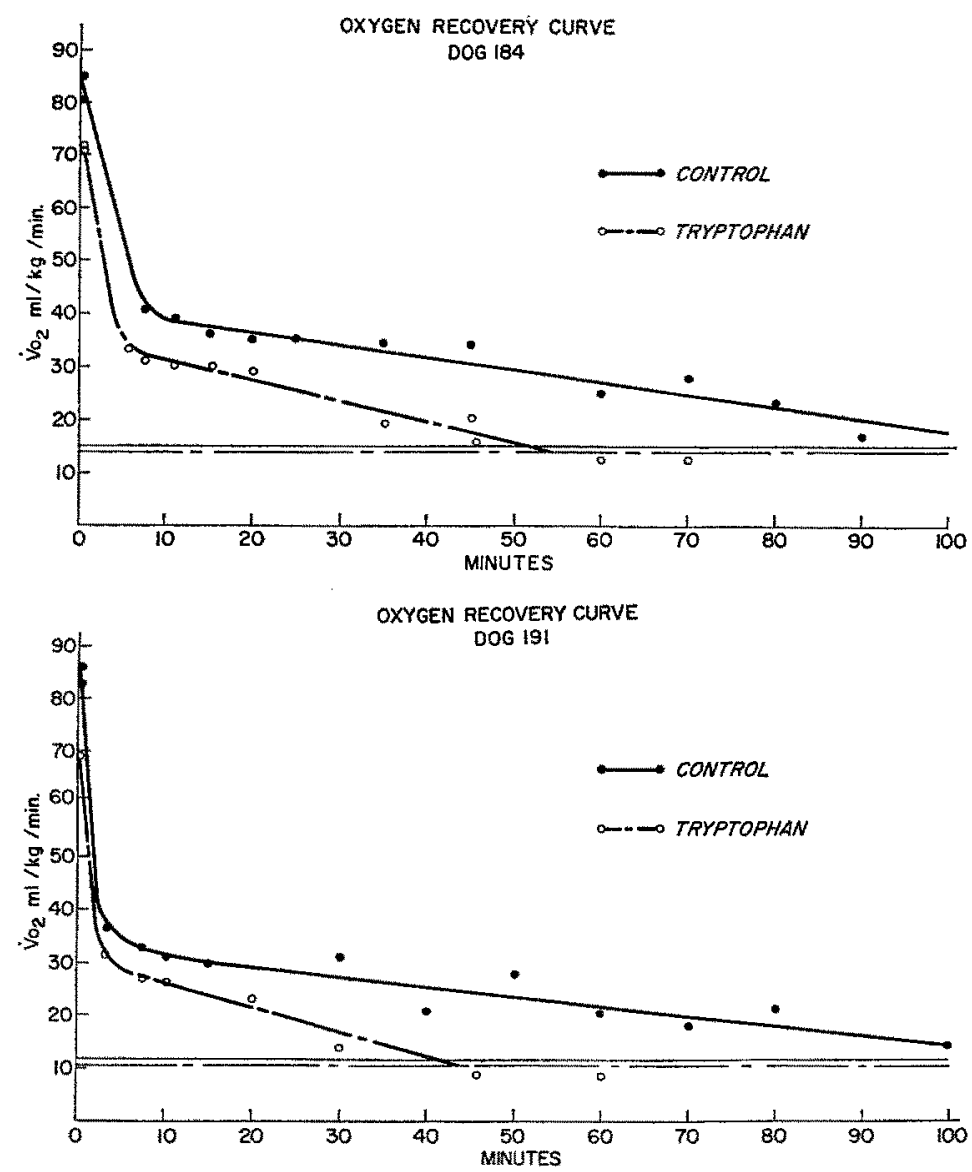

Fig. 1. Oxygen recovery curves for dogs following a $19-\mathrm{min}$ treadmill run at $4 \mathrm{mph}$ with a 20 percent grade. The lines at the bottom of each graph represent resting $\dot{V}_{\mathrm{O}_{2}}$ values. The $\dot{V}_{\mathrm{O}_{2}}$ values obtained during the last minute of exercise are plotted at zero time

$3 \mathrm{ml} / \mathrm{kg} / \mathrm{min}$. During the tryptophan tests 4 of the 5 dogs showed a decrease in exercise oxygen consumption. The values ranged from $\mathbf{5 7 . 0 2}$ to $90.43 \mathrm{ml} / \mathrm{kg} / \mathrm{min}$. The mean value for the tryptophan tests was $72.0 \pm 5.33 \mathrm{ml} / \mathrm{kg} / \mathrm{min}$; the mean reduction was 11.01 percent which was significant at the 0.05 level. During the fasting test, the oxygen consumption for the last minute of exercise was decreased by $5.34 \mathrm{ml}$ / $\mathrm{kg} / \min$ (Fig. 2).

\section{Oxygen Debt}

The oxygen debt measurements for the control tests were recorded for as long as $100 \mathrm{~min}$. The debts ranged from 11.67 to 30.791 with a 

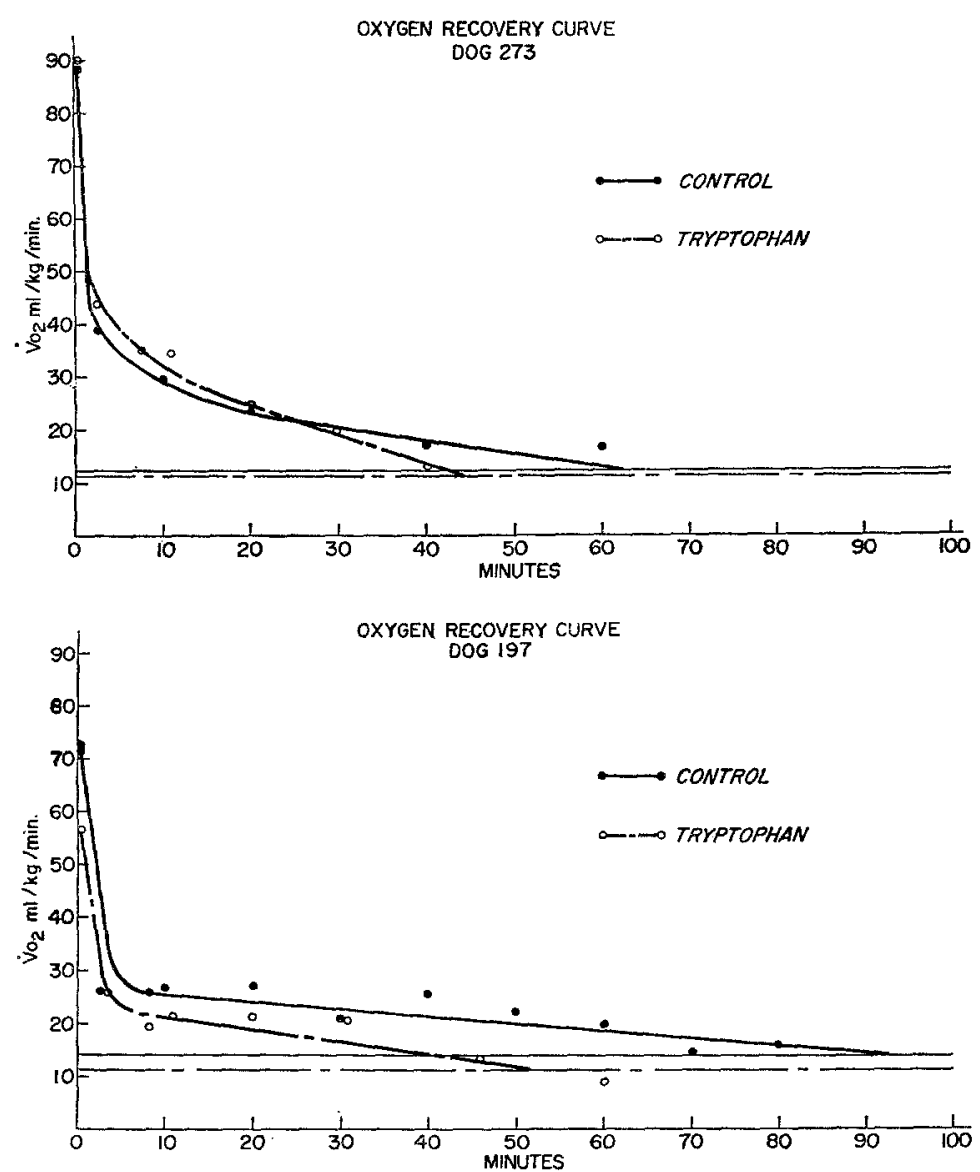

Fig. 1

mean of $21.26 \pm 3.221$ (Table 2). Dog No. 184 had the largest debt and also had the highest peak lactate value $(4.98 \mathrm{mM} / 1)$. The oxygen debts for the tryptophan tests ranged from 9.46 to $12.47 \mathrm{l}$ with a mean of $10.72 \pm 0.561$. The mean reduction in oxygen debt for the tryptophan tests was 44.0 percent which was significant at the 0.05 level. The oxygen recovery curves for all 5 dogs are shown in Figs. 1 and 2 . The response observed in dog No. 273 was quite different than that observed in the other 4 dogs. Although his arterial lactate increased to $4.82 \mathrm{mM} / 1$ his control oxygen debt was much smaller than the debts observed in the other 4 dogs. He showed only an 8.2 percent reduction during the tryptophan test.

The oxygen debt recorded for dog No. 272 (Fig. 2) during the fasting test was 11.181 which was a 52.5 percent reduction from the control 

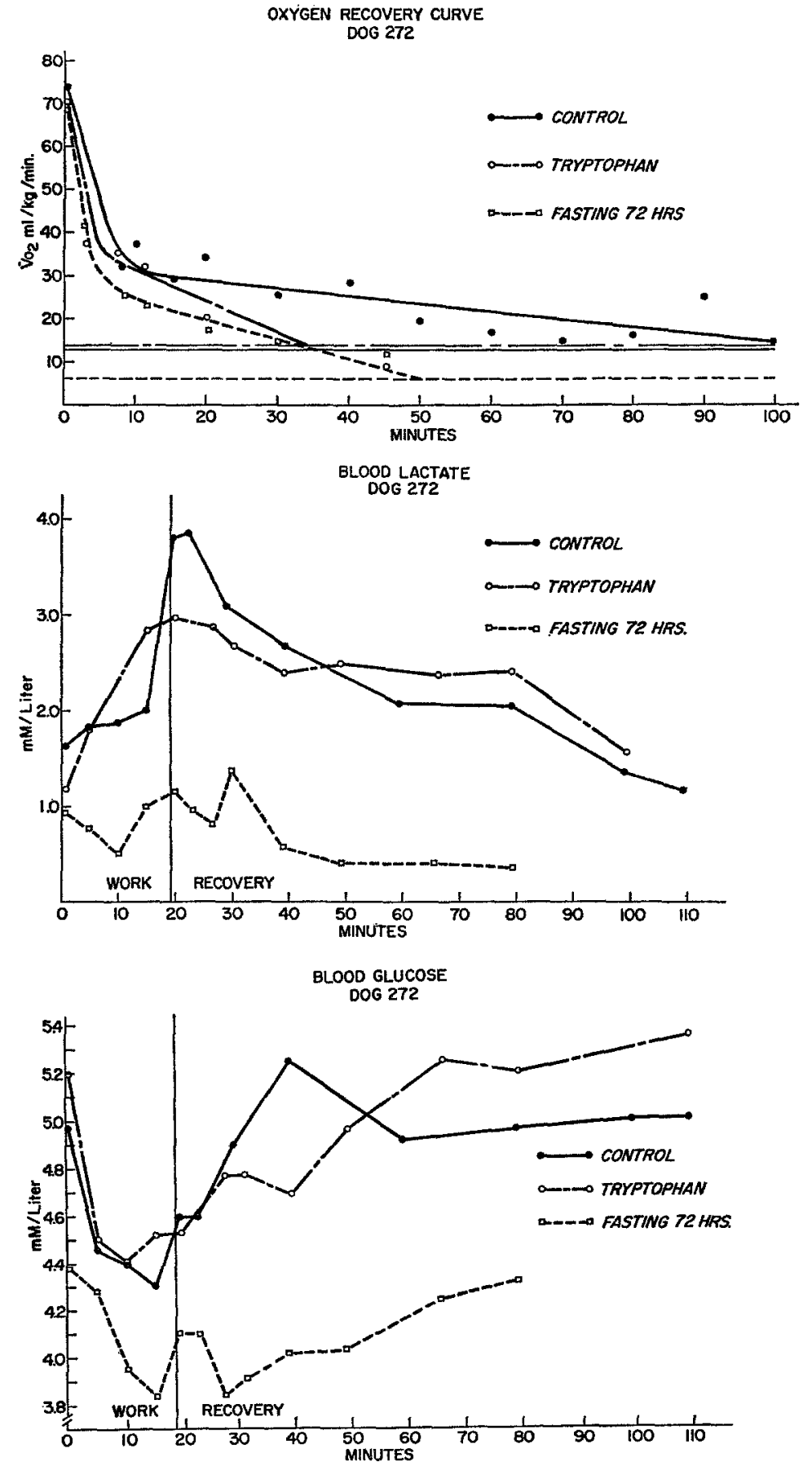

Fig. 2. Data obtained from dog No. 272 during a 19-min run on the treadmill at $4 \mathrm{mph}$ with a 20 percent grade 
test. His tryptophan test debt was 9.461 which was a 59.8 percent reduction from the control.

\section{Arterial Lactate and Glucose}

The resting arterial lactate values ranged from 1.45 to $2.01 \mathrm{mM} / 1$ for the control tests. During the tryptophan tests the resting lactate concentration was decreased slightly in all 5 dogs. The decreases ranged from 0.18 to $0.42 \mathrm{mM} / \mathrm{l}$. Arterial lactate reached its peak concentration at the end of exercise or during the first few minutes of recovery. Peak values for the control tests (Table 2), ranged from 3.83 to $4.98 \mathrm{mM} / \mathrm{l}$ with a mean of $4.44 \pm 0.27 \mathrm{mM} / \mathrm{l}$. The values toward the end of recovery were generally lower than they were at rest even though oxygen consumption remained elevated. The lactate values recorded during the fasting test (Fig. 2), were in all instances lower than the control test resting concentration. The resting level during fasting was $0.93 \mathrm{mM} / \mathrm{l}$. During exercise the concentration increased to only $1.23 \mathrm{mM} / \mathrm{l}$.

The mean resting arterial glucose values were 4.90 and $4.96 \mathrm{mM} / \mathrm{l}$ for the control and tryptophan tests respectively. The glucose concentration dropped during the first 10 to $15 \mathrm{~min}$ of exercise, then increased to or above the resting level. Fig. 2 is a typical example of the arterial glucose changes observed during the control and tryptophan tests. The glucose values recorded during the fasting test (Fig. 2), show that dog No. 272 was approaching a state of hypoglycemia. His glucose concentration dropped to a low of $3.85 \mathrm{mM} / 1$.

\section{Rectal Temperature}

The mean resting rectal temperatures were 102.4 and $102.5^{\circ} \mathrm{F}$ for the control and tryptophan tests respectively. The peak rectal temperatures for the control tests ranged from 105.8 to $107.6^{\circ} \mathrm{F}$ with a mean of 106.6 $\pm 0.42^{\circ} \mathrm{F}$. During the tryptophan tests the peak rectal temperatures ranged from 105.0 to $106.6^{\circ} \mathrm{F}$ with the mean of $105.6 \pm 0.34^{\circ} \mathrm{F}$ (Table 2).

\section{Discussion}

Blood lactate measurements have been used since the early 1900 's to estimate the anaerobic metabolism associated with any given bout of exercise. Although Margaria et al. [27], reported in 1933 that at light work loads no increase in blood lactate could be observed, Jöbsis and Duffield [18] have recently found in isolated muscle that lactate is formed after four and possibly after two muscle twitches. When lactate is formed in contracting skeletal muscle the only major means by which it can be removed is by diffusion into the blood stream $[6,37,38]$. Once lactate has diffused into the blood stream it can be utilized by other tissues. 
such as the myocardium $[2,21]$, skeletal muscle $[5,10,12]$, liver $[5,35,36]$, and kidney [25]. With the exception of the liver, the rate of lactate uptake by these tissues during exercise has not been determined.

The relationship between oxygen debt and the removal of lactate by these various tissues now becomes the important question. The fate of lactate removed by the heart or skeletal muscle has to be either storage or metabolism to carbon dioxide and water because these tissues lack necessary enzymes for gluconeogenesis [39]. The metabolic rate of the myocardium and skeletal muscle is determined by the energy status of the cells, i.e., the levels of ATP, ADP, and $P_{i}$ [32]. Although lactate is metabolized by these tissues it does not control the metabolic rate and therefore cannot be responsible for oxygen debt in this situation. The lactate utilized by these tissues probably replaces some other substrate. Issekutz et al. [16], have shown that an increase in lactate metabolism results in a decrease in glucose and free fatty acid metabolism without influencing or increasing the resting oxygen consumption. In the case of the liver (and possibly the kidneys) most of the lactate is converted to glucose via gluconeogenesis. Gluconeogenesis is an energy consuming process requiring six moles of high energy phosphate for every mole of glucose formed [22]. The addition of gluconeogenic substrates such as lactate to liver or kidney tissue greatly stimulates oxygen consumption as well as gluconeogenesis $[23,24,34]$. It should be also noted that the increase in oxygen consumption induced by lactate is always in excess of that calculated to be required for the synthesis of ATP necessary for the concomitant gluconeogenesis. The exact reason for this "oxygen wasting" effect is unknown [30]. Since it has been demonstrated that the liver does remove lactate which is produced during exercise [5, 12, 35, 36], it appears that the lactacid mechanism has to be involved in oxygen debt as long as lactate is being removed by the liver during recovery. The results presented in Table 2 and in Figs. 1 and 2 support the concept that the lactacid as well as the alactacid mechanism is involved in oxygen debt.

\section{Oxygen Consumption}

The mean resting consumption value for the control tests, $13.39 \mathrm{ml} /$ $\mathrm{kg} / \mathrm{min}$, is higher than the 8 to $9 \mathrm{ml} / \mathrm{kg} / \mathrm{min}$ reported by Issekutz et al. [17] and by Young et al. [42]. Although these dogs sat "quietly" on the treadmill while the resting sample was being collected they were unable to reach the "state" obtained by the other investigators. The resting rectal temperatures also support this view. The mean resting oxygen consumption for the tryptophan tests, $12.18 \mathrm{ml} / \mathrm{kg} / \mathrm{min}$, was lower than the control value; but, because of the amount of variability between control tests, this reduction is not considered to be meaningful. The 
resting values for the two control tests showed a mean difference of 20.1 percent. The lowest resting value obtained was $6.73 \mathrm{ml} / \mathrm{kg} / \mathrm{min}$ which was obtained during the fasting test for dog No. 272. Young [41] has reported similar values for fasting dogs.

The mean oxygen consumption value measured during the last minute of exercise for the control tests was $80.67 \mathrm{ml} / \mathrm{kg} / \mathrm{min}$. This value is comparable to values reported by Young et al. [42] and by Issekutz et al. [17] for dogs performing similar work loads. The values obtained for the two control tests showed a mean difference of $3 \mathrm{ml} / \mathrm{kg} / \mathrm{min}$. The oxygen consumption values during the last minute of exercise for the tryptophan tests showed a mean reduction of 11.0 percent from the control values. This reduction in oxygen consumption is not surprising since Rowell et al. [36] have shown that lactate removal by the liver is proportional to the arterial concentration. In the present study lactate was at its peak concentration at or near the end of exercise. Rowell et al. [36] also found that during prolonged work the lactate concentration reached a peak at approximately $10 \mathrm{~min}$ and then declined throughout the work period. These investigators stated that lactate could not be involved in oxygen debt since most of the lactic acid that had been produced had been removed before the cessation of the work period. The results obtained from the present study indicate that lactate removal during exercise does influence the oxygen consumption. Therefore, during prolonged work one might conclude that part of the "future" debt is actually being paid back before the recovery period.

\section{Oxygen Debt}

When tryptophan and quinolinic acid were administered to block the removal of lactate by the liver, oxygen debt was reduced by 44 percent. This value may actually be a slight underestimate of the involvement of the lactacid mechanism in oxygen debt since one of the dogs showed only an 8.2 percent reduction. The reason for this wide variance is unknown. The average reduction for the other 4 dogs was 53 percent. When fasting was used to eliminate the accumulation of lactate during exercise, oxygen debt was reduced to the same level as when lactate removal by the liver was blocked. Thus, two different approaches have demonstrated that the lactacid mechanism is, indeed, involved in oxygen debt.

The present authors suggest that the oxygen debt measured during the tryptophan test is a good approximation of the alactacid debt. When Margaria, Edwards and Dill [27] first proposed the lactacid-alactacid concept of oxygen debt, they suggested that the alactacid phase was associated with the initial rapid decline in oxygen consumption which took place during the first few minutes of recovery; however, they had 
no biochemical data to support their suggestion. In the present study, the involvement of lactate in endothermic reactions has been eliminated. Therefore, the oxygen debts measured during the tryptophan tests must be alactacid debts. The alactacid debts measured in the present study last for a much longer period of time $(45$ to $60 \mathrm{~min}$ ) than was suggested by Margaria et al. [27]. These debts are also composed of a rapid and slow component. Whether or not this form of the alactacid curve is solely a characteristic of the animal used in the study remains to be determined. The slow component might be associated with the panting mechanism which is evoked by the dog to dissipate heat. This slow component has also been observed at lighter work loads.

\section{Arterial Lactate}

The arterial lactate reached its peak concentration at the end of exercise or during the first few minutes of recovery. This same pattern was observed by Issekutz et al. [17]. The values toward the end of recovery were generally lower than they were at rest, even though the oxygen consumption was still elevated. It must be realized that the arterial concentration is influenced by the rate of production as well as the rate of removal. Therefore, blood lactate levels should not be used alone to predict the state of lactate metabolism in the body.

The arterial lactate values recorded during the tryptophan tests were generally lower than those recorded for the control tests. Unfortunately the exact reason for the reduction is unknown. However, with a reduction in lactate formation, one would expect an increase in oxygen consumption during exercise if oxygen availability is not rate-limiting. The opposite results were observed in the present study.

One possible explanation involves the conversion of tryptophan and quinolinic acid to nicotinic acid which has been observed following administration of these agents to animals (personal communication: L. M. Henderson, University of Minnesota). Paul et al. [31] have demonstrated that the administration of nicotinic acid to dogs results in a decrease in fatty acid metabolism with a concomitant increase in glucose oxidation. Oxygen consumption remained unchanged. With an increase in glucose oxidation to replace fatty acid metabolism one would expect a decrease in lactate formation. This may well be what happened in our dogs but unfortunately we have no data regarding fatty acid metabolism to substantiate this hypothesis.

Regardless of the factor(s) involved in the reduction of lactate found during the tryptophan tests, it must be remembered that the involvement of lactate in oxygen debt has been eliminated when the conversion of lactate back to glucose is blocked. 


\section{Rectal Temperature}

The mean resting rectal temperature was $102.4^{\circ} \mathrm{F}$. This value is slightly higher than the value which is considered to be "normal" for mongrel dogs [4]. We believe the higher value is associated with the anticipation of running on the treadmill. Gollnick and Ianuzzo [11] have reported similar observations in rats who were placed in treadmills.

The mean peak rectal temperature for the control runs was $106.6^{\circ} \mathrm{F}$ which indicates that the work load was strenuous but not exhaustive. The peak temperatures recorded during the tryptophan tests were lower than the control test values. Since the liver is normally a very active metabolic organ during exercise [36], one might anticipate a reduction in core temperature when aspects of liver metabolism are blocked. The tremendous amount of heat generated by the liver during exercise was observed by Rowell et al. [35] when they recorded hepatic venous blood temperatures which were as much as $1.5^{\circ} \mathrm{C}$ higher than the rectal temperature.

\section{Bibliography}

1. Alpert, N. R., Root, W. S.: Relationship between excess respiratory metabolism and utilization of intravenously infused sodium racemic lactate and $L(-)$ lactate. Amer. J. Physiol. 177, 455-462 (1954).

2. Carlsten, A., Hallgren, B., Jagenburg, R., Șanborg, A., Werko, L.: Myocardial metabolism of glucose, lactic acid, amino acids, and fatty acids in healthy human individuals at rest and at different work loads. Scand. J. clin. Lab. Invest. 13, 418-428 (1961).

3. Consolazio, C. F., Johnson, R. E., Pecora, L. J.: Physiological Measurements of Metabolic Functions in Man, p. 8. New York: MeGraw-Hill 1963.

4. Dukes, H. H.: The Physiology of Domestic Animals, p. 638. Ithica (N.Y.): Comstock 1955 .

5. Eggleton, M. G., Evans, C. L. : The lactic acid content of the blood after muscular conttracion under experimental conditions. J.Physiol.(Lond.) 70, 269-293 (1930).

6. Flock, E. V., Ingle, D. J., Bollman, J. L.: Formation of lactic acid, an initial process in working muscle. J. biol. Chem. 129, 99-110 (1939)..

7. Foss, M. L., Barnard, R. J.: A vest to protect exposed chronic implants in dogs. Lab. Animal Care 19, 113-114 (1969).

8. Foster, D. O., Lardy, H. A., Ray, P. D., Johnston, J. B.: Alteration of rat liver phosphoenolpyruvate carboxykinase activity by L-tryptophan in vivo and metals in vitro. Biochemistry 6, 2120-2128 (1967).

9. - Ray, P. D., Lardy, H. A.: A paradoxical in vivo effect of L-tryptophan on the phosphoenolpyruvate carboxykinase of rat liver. Biochemistry 5, 563-569 (1966).

10. Freyschuss, U., Strandell, T.: Limb circulation during arm and leg exercise in supine position. J. appl. Physiol. 23, 163-170 (1967).

11. Gollnick, P. D., Ianuzzo, C. D.: Colonic temperature response of rats during exercise. J. appl. Physiol. 24, 747-750 (1968).

12. Harris, P., Bateman, M., Gloster, J.: The regional metabolism of lactate and pyruvate during exercise in patients with rheumatic heart disease. Clin. Sci. 23, $545-560(1962)$. 
13. Hill, A. V., Long, C. N. H., Lupton, H.: Muscular exercise, lactic acid, and the supply and utilization of oxygen. Part I. Introduction. Proc. roy. Soc. B 96, $438-444(1924)$.

14. - - - Muscular exercise, lactic acid, and the supply and utilization of oxygen. Part VI. The oxygen debt at the end of exercise. Proc. roy. Soc. B 97, $127-137(1924)$.

15. Huckabee, W. E.: Relationships of pyruvate and lactate during anaerobic metabolism. II. Exercise and formation of $\mathrm{O}_{2}$-debt. J. clin. Invest. 37, 255--263 (1958).

16. Issekutz, B., Jr., Miller, H. I., Paul, P., Rodahl, K.: Effect of lactic acid on free fatty acids and glucose oxidation in dogs. Amer. J. Physiol. 209, 1137-1144 (1965).

17. - - Rodahl, K.: Lipid and carbohydrate metabolism during exercise. Fed. Proc. 85, 1415-1420 (1966).

18. Jöbsis, F.F., Duffield, J. C.: Oxidative and glycolytic recovery metabolism in muscle. J. gen. Physiol. 50, 1009-1047 (1967).

19. Jonsson, A., Madison, L. L.: The role of the kidney in blood glucose homeostasis during prolonged starvation. J. clin. Invest. 47, 52a (1968).

20. Kayne, H. L., Alpert, N. R.: Oxygen consumption following exercise in the anesthetized dog. Amer. J. Physiol. 206, 51-56 (1964).

21. Keul, J., Doll, F., Steim, H., Fleer, U., Reindell, H.: Über den Stoffwechsel des menschlichen Herzens. III. Der oxydative Stoffwechsel des menschlichen Herzens unter verschiedenen Arbeitsbedingungen. Pflügers Arch. ges. Physiol, $282,43-53(1965)$.

22. Krebs, H. A.: Gluconeogenesis. Proc. roy. Soc. B 159, 545-564 (1964).

23. - Bennett, D. A. H., de Gasquet, P., Gascoyne, T., Yoshida, T.: Renal gluconeogenesis. The effect of diet on the gluconeogenic capacity of rat-kidneycortex slices. Biochem. J. 86, 22-27 (1963).

24. - Dierks, C., Gascoyne, T.: Carbohydrate synthesis from lactate in pigeonliver homogenate. Biochem. J. 93, 112-121 (1964).

25. Levy, M. N.: Uptake of lactate and pyruvate by intact kidney of the dog. Amer. J. Physiol. 202, 302-308 (1962).

26. Marbach, E. P., Weil, M. H.: Rapid enzymatic measurement of blood lactate and pyruvate. Clin. Chem. 13, 314-325 (1967).

27. Margaria, R., Edwards, H. T., Dill, D. B.: The possible mechanisms of contracting and paying the oxygen debt and the role of lactic acid in muscular contraction. Amer. J. Physiol. 106, 689-715 (1933).

28. Meyerhof, O.: Die Energieumwandlungen im Muskel. III. Kohlenhydrat- und Milchsäureumsatz im Froschmuskel. Pfügers Arch. ges. Physiol. 185, 11-32 (1920).

29. - Die Energieumwandlungen im Muskel. IV. Ưber die Milchsäurebildung in der zerschnittenen Muskulatur. Pflügers Arch. ges. Physiol. 188, 114-160 (1921).

30. Newsholme, E. A., Grevers, W.: Control of glycolysis and gluconeogenesis in liver and kidney cortex. Vitamins Hormones 20, 1-87 (1967).

31. Paul, P., Issekutz, B., Miller, H. I.: Interrelationship of free fatty acids and glucose metabolism in the dog. Amer. J. Physiol. 211, 1313-1320 (1966).

32. Racker, E.: Mechanisms in Bioenergetics, p. 253. New York: Academic Press 1965.

33. Ray, P. D., Foster, D. O., Lardy, H. A.: Paths of carbon in gluconeogenesis and lipogenesis at the level of phosphoenolpyruvate formation. J. biol. Chem. 241, 3904-3908 (1966). 
34. Ross, B. D., Hems, R., Krebs, H. A.: The rate of gluconeogenesis from various precursors in the perfused rat liver. Biochem. J. 102, 942-951 (1967).

35. Rowell, L. B., Brengelmann, G. L., Blackmon, J. R., Twiss, R. D., Kusumi, F.: Splanchnic blood flow and metabolism in heat-stressed man. J. appl. Physiol. 24, $475-484(1968)$.

36. - Kraning II, K. K., Evans, T. O., Kennedy, J. W., Blackmon, J. R., Kusumi, F.: Splanchnic removal of lactate and pyruvate during prolonged exercise in man. J. appl. Physiol. 21, 1773-1783 (1966).

37. Sacks, J., Sacks, W. C.: Carbohydrate changes during recovery from muscular contraction. Amer. J. Physiol. 112, 565-572 (1935).

38. - - Shaw, J. R.: Carbohydrate and phosphorus changes in prolonged muscular contractions. Amer. J. Physiol. 118, 232-240 (1937).

39. Utter, M. F., Keech, D. B.: Pyruvate carboxylase. II. Properties. J. biol. Chem. 238, 2609-2614 (1963).

40. Veneziale, C. M., Walter, P., Kneer, N., Lardy, H. A.: Influence of L-tryptophan and its metabolites on gluconeogenesis in the isolated, perfused liver. Biochemistry 6, 2129-2138 (1967).

41. Young, D. R. : Effect of food deprivation on treadmill running in dogs. J. appl. Physiol. 14, 1018-1022 (1959).

42. - Mosher, R., Erve, P., Spector, H.: Energy metabolism and gas exchange during treadmill running in dogs. J. appl. Physiol. 14, 834-838 (1959).

Dr. R. James Barnard

Department of Medicine

U.C.L.A. School of Medicine

Los Angeles, California 90024 U.S.A.
Dr. Merle L. Foss

Department of Physical Education

University of Michigan

Ann Arbor, Michigan U.S.A. 